\title{
Effects of Repetitive Peripheral Magnetic Stimulation Over Vastus Lateralis in Patients After Hip Replacement Surgery
}

\author{
Junghyun Baek, MD , Nohkyoung Park, MD${ }^{1}$, Bongju Lee, $\mathrm{MD}^{2}$, \\ Sungju Jee, $\mathrm{MD}, \mathrm{PhD}^{3}$, Shinseung Yang, $\mathrm{MD}, \mathrm{PhD}^{3}$, Sangkuk Kang, $\mathrm{MD}$, $\mathrm{PhD}^{1}$
}

\begin{abstract}
Departments of ${ }^{1}$ Physical Medicine and Rehabilitation, ${ }^{2}$ Orthopedic Surgery, Sun General Hospital, Daejeon; ${ }^{3}$ Department of Physical Medicine and Rehabilitation, Chungnam National University Hospital, Daejeon, Korea
\end{abstract}

Objective To investigate the effects of repetitive peripheral magnetic stimulation (rPMS) on the vastus lateralis (VL) in the early stage after hip replacement surgery.

Methods Twenty-two patients who underwent hip replacement after proximal femur fracture were included in this study. After hip surgery, the experimental group was applied with 15 sessions of $10 \mathrm{~Hz}$ rPMS over the VL 5 times per week for 3 weeks, while the control group took sham stimulation. All patients were also given conventional physical therapy. The VL strength was measured with the root mean square (RMS) value of the VL with surface electromyography technique. The ratio of RMS values between fractured and unfractured legs and tandem stand test were used to assess standing balance. Usual gait speed was measured to evaluate gait function. Pain in two groups was assessed with visual analog scale (VAS).

Results Both RMS value of the VL and the ratio of RMS values after rPMS were significantly improved $(\mathrm{p}<0.05)$. Also, tandem standing time and usual gait speed in rPMS group were dramatically increased $(\mathrm{p}<0.05)$. However, no significant difference in VAS was found between the two groups after 3 weeks.

Conclusion rPMS on the VL improved muscle strength, standing balance and gait function in the early stage after hip surgery. Therefore, rPMS could be applied to patients who cannot take electrical stimulation due to pain and an unhealed wound.

Keywords Repetitive peripheral magnetic stimulation, Hip replacement surgery, Quadriceps strength, Proximal femur fracture

Received May 19, 2017; Accepted July 3, 2017

Corresponding author: Sangkuk Kang

Department of Physical Medicine and Rehabilitation, Sun General Hospital, 29 Mokjung-ro, Jung-gu, Daejeon 34811, Korea. Tel: +82-42-220-8468, Fax: +82-303-3130-8468, E-mail: rmactksk@daum.net

ORCID: Junghyun Baek (http://orcid.org/0000-0002-7296-0153); Sangkuk Kang (http://orcid.org/0000-0003-0563-3280); Nohkyoung Park (http:// orcid.org/0000-0002-6950-5387); Bongju Lee (http://orcid.org/0000-0002-3514-5037); Sungju Jee (http://orcid.org/0000-0002-9400-9609); Shinseung Yang (http://orcid.org/0000-0002-6831-1556).

() This is an open-access article distributed under the terms of the Creative Commons Attribution Non-Commercial License (http://creativecommons.org/ licenses/by-nc/4.0) which permits unrestricted noncommercial use, distribution, and reproduction in any medium, provided the original work is properly cited. Copyright $\odot 2018$ by Korean Academy of Rehabilitation Medicine 


\section{INTRODUCTION}

Hip fracture is the leading cause of functional impairment, disability, and death in elderly people. Despite successful surgical treatments, the majority of patients with hip fracture do not recover their functions after surgery [1]. Although many factors, such as age, mental status, pre-fracture functioning, comorbidity or nutritional status, are involved in continued disability after hip fracture, the decrease of quadriceps strength is reported to be a significant cause, as well as a correctable one [24]. Aniansson et al. [5] performed a muscle biopsy at the vastus lateralis (VL) in patients with hip fracture and reported a considerable decrease of fast-twitch fiber size, which is important for the generation of maximal power, measured through cross-sectional area. Also, Lamb et al. [6] suggested that the extensor power of the fractured leg is the most important factor for deciding mobility in patients with proximal femur fracture.

Neuromuscular electrical stimulation is a treatment modality widely used in practice because it can improve the strength of the injured muscle by stimulating the motor and sensory pathways [7-9]. However, electrical stimulation is difficult to apply when severe pain and unhealed wounds are present in the early stage after surgery because it requires pads on the skin and induces pain during stimulation. Braid et al. [10] reported that there was no significant improvement of muscle strength and level of disability after electrical stimulation on quadriceps due to local discomfort and pain in the early stage after surgical treatment in elderly patients with hip fracture.

As a non-invasive peripheral simulation method, repetitive peripheral magnetic stimulation (rPMS) is a novel and innovative therapeutic option that can provide a stimulus to the muscles, nerves or spinal roots. The rPMS applied to the muscle areas innervated by the terminal branches can improve motor functions by not only creating muscle contraction but also increasing the activity of motor cortex through massive proprioceptive inputs to the central nervous system [11-16]. Also, rPMS can penetrate high-resistance tissues such as skin, fat and cranial bone. It causes less pain than electrical stimulation because it can pass through the cutaneous nociceptive receptor in the skin and stimulate the deeper neuromuscular system $[13,17,18]$. As its advantages, rPMS can produce higher muscle toque than electrical stimulation, is easy to apply to children as it doesn't require pads and causes less pain, and can give an individual stimulus to different muscles $[13,19,20]$. Although the application of rPMS to a variety of situations has drawn popularity in the field of clinical neurology, no study has been conducted to strengthen the knee extensor muscle and improve the mobility in rehabilitation for patients with a proximal femur fracture.

In this study, we investigate whether rPMS can increase the strength of the VL which are the most important for the recovery of mobility function in patients who underwent hip replacement surgery and also improve standing balance and gait function of such patients.

\section{MATERIALS AND METHODS}

\section{Subjects}

The participants of this study were patients who underwent primary hip replacement from an orthopedist due to unilateral proximal femur fracture between June 2016 and March 2017. The pattern of femur fracture (femoral neck/intertrochanteric) and the type of surgical fixation (total hip arthroplasty/hemiarthroplasty) were confirmed by operation records and radiological films. Patients were excluded if they satisfied any of the following criteria: (1) those who were found to be unable to walk independently (with or without monocane) before fracture through history taking, (2) those who have unstable medical conditions except a chronic disease under control, (3) those who have psychiatric problems, (4) those who cannot follow the instruction of the interviewer due to severe cognitive dysfunction, (5) those who have additional orthopaedic pathology that can cause abnormality in motor function, and (6) those who have disorders in the central nervous and peripheral nervous systems. The protocol was approved by the Institutional Review Board of Sun General Hospital (No. DSH-인-16-04).

A prospective, randomized, double-blind study was used. The 24 patients were selected for this study, with 12 patients randomly assigned to the rPMS group and the sham group, respectively (Fig. 1). Age, gender, body mass index (BMI), and the history of past and present chronic diseases were checked through medical notes and structural interviews. All participants gave written informed consent. All patients were treated with conventional 


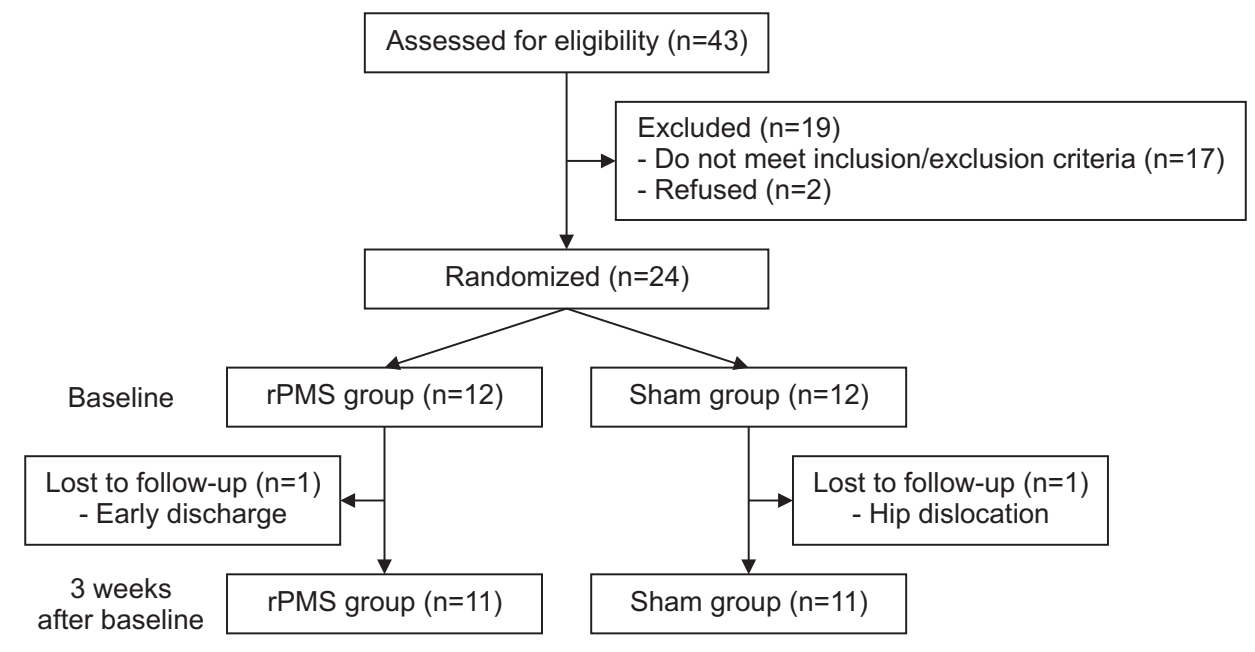

Fig. 1. Flow chart of the study. rPMS, repetitive peripheral magnetic stimulation.

physical therapy starting with isometric exercise, and then proceeding to gait training until discharge.

\section{Repetitive peripheral magnetic stimulation}

For the rPMS group, the optimal location was decided, where muscle contraction was the most prominent when a figure-eight stimulation coil (Magstim Rapid'; Magstim Company Ltd., Carmarthenshire, UK) was tangentially placed on the skin between the upper one-third and the lower two-thirds of the VL while patients were lying on their back in the bed [21]. The intensity of stimulation was individually set at the level where the visible movement of the knee is triggered. Each session consisted of 200 trains with a stimulation frequency of $10 \mathrm{~Hz}$ at a train duration of 1.5 seconds and inter-train interval of 6 seconds. Thus a total of 3,000 stimuli over 25 minutes were delivered per a single session (Fig. 2). For the control group, the angle of the coil was perpendicular, not tangential, to the muscle belly for sham stimulation. In order to produce as small energy as possible, the intensity was set at $5 \%$ of maximal power, allowing the participants to hear the sound of the rPMS machine [22]. Both groups were applied with stimulation 5 times per week for 3 weeks from the 4 th to 6 th days after surgery.

\section{Evaluation methods}

In order to measure the muscle strength of the VL, the surface electromyographic (EMG) technique proposed by Alkner et al. [23] was used. The participants sat in a high chair with a string tied to their leg $10 \mathrm{~cm}$ above the ankle joint and with their hip joint positioned at the angle of $75^{\circ}$ and the knee joint at $90^{\circ}$. To obtain the EMG of the VL

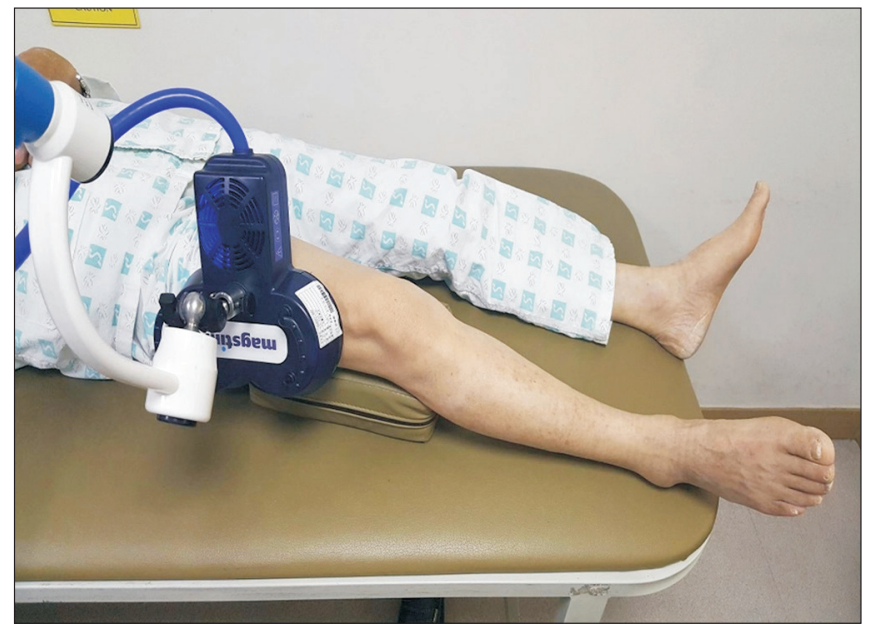

Fig. 2. The magnetic coil was located over the motor point of the vastus lateralis on the fractured side.

using the disposable bipolar Ag-Ag/CL surface electrode, a line was drawn between the head of greater trochanter, and the lateral femoral epicondyle and a recording electrode was placed on the midpoint and $20 \mathrm{~mm}$ distal site, respectively. A reference electrode was attached to the proximal tibial bone. Before the initial assessment, patients repeated submaximal isometric knee extension 10 times as a warm-up. Then, the EMG signal at the maximal voluntary contraction was obtained by making patients maintain their muscle contraction for 3 seconds when voluntary quadriceps contraction reached its maximum level after increasing it gradually. After being filtered with low and high cut-off frequencies at 20 and $500 \mathrm{~Hz}$, respectively, the root mean square (RMS) values of the raw EMG signal were averaged over the open 1,000 ms time 
window showing highest values, and then two trials were performed, and their average value was used as the final value. In addition, the ratio of maximal isometric peak force of the VL between fractured and the non-fractured legs was calculated by measuring the RMS value of the VL with the same method in the contralateral leg.

The tandem stand test proposed by Guralnik et al. [24] was used to assess standing balance. Patients were asked to locate the heel of the fractured side directly in front of the toes of the opposite foot. A demonstration was provided by the interviewer before the test. While the participants were placing their feet, they were asked if they were ready for the test, with one of their arms supported by the interviewer, and then time measurement was started after their supporting arm was released. When the participants moved their feet or held the interviewer for support, or when 10 seconds had elapsed, time measurement was stopped.

To evaluate gait function, the usual gait speed test proposed by Guralnik et al. [25] was used. Gait speed was measured for the two distances of $10 \mathrm{ft}(3.05 \mathrm{~m})$ and 50 $\mathrm{ft}(15.25 \mathrm{~m})$, which are the minimum and maximum distances needed to walk around a house [26]. By drawing thick red lines at the starting point, $10 \mathrm{ft}$ and $50 \mathrm{ft}$ on the floor of the physical therapy room, the ability and time required to complete the distances were recorded. An assistant walked along with patients by keeping a length of one arm from the patients to respond to patients' unexpected loss of balance. Time measurement was started when patients crossed the starting point and stopped when the patients reached or crossed the finishing line. Patients were allowed to use walking aids with which they were the most confident. For example, when patients were in transition, such as from a walking frame to a cane, a walking aid that can help patients walk the fastest was selected for the test.

Visual analog scale (VAS) was measured to assess the degree of pain on the hip. With the VAS of 0 being no pain and 10 being an unbearable pain, patients were asked to score their pain level.

All outcome assessments were evaluated before stimulation and after 3 weeks of stimulation.

\section{Statistical analysis}

The SPSS version 19.0 for Windows (IBM, Armonk, NY, USA) was employed for statistical analysis. Mann-
Whitney U-test, chi-square test, and Fisher exact test were used to compare the demographic characteristics of the two groups. Outcome measures were compared with the Wilcoxon signed rank test within each the rPMS and control groups, and Mann-Whitney U-test was used for comparing the two groups. Statistical significance was assumed at $\mathrm{p}<0.05$ and a confidence interval (CI) of $95 \%$.

\section{RESULT}

Since 1 participant was discharged early from the rPMS group and 1 participant was excluded from the sham group due to hip dislocation, a total 22 subjects were finally included for statistical analysis. No specific difference was found in the baseline characteristics consisting of age, sex, BMI, medical conditions, fracture pattern, surgical type and days post-operation to baseline between the two groups (Table 1).

Table 1. Demographic characteristics of patients both rPMS and sham groups

\begin{tabular}{|c|c|c|}
\hline & $\begin{array}{l}\text { rPMS group } \\
(n=11)\end{array}$ & $\begin{array}{l}\text { Sham group } \\
(\mathrm{n}=11)\end{array}$ \\
\hline Age (yr) & $77.09 \pm 6.78$ & $80.36 \pm 7.97$ \\
\hline \multicolumn{3}{|l|}{ Gender } \\
\hline Male & 1 & 2 \\
\hline Female & 10 & 9 \\
\hline $\mathrm{BMI}\left(\mathrm{kg} / \mathrm{m}^{2}\right)$ & $22.02 \pm 3.77$ & $21.14 \pm 2.86$ \\
\hline Medical condition & $1.64 \pm 0.67$ & $1.82 \pm 0.87$ \\
\hline \multicolumn{3}{|l|}{ Fractured side } \\
\hline Right & 6 & 5 \\
\hline Left & 5 & 6 \\
\hline \multicolumn{3}{|l|}{ Type of fracture } \\
\hline Femoral neck & 5 & 5 \\
\hline Intertrochanteric & 6 & 6 \\
\hline \multicolumn{3}{|l|}{ Type of operation } \\
\hline THA & 7 & 6 \\
\hline Hemiarthroplasty & 4 & 5 \\
\hline $\begin{array}{l}\text { Days post-operation from } \\
\text { baseline }\end{array}$ & $4.73 \pm 0.90$ & $4.55 \pm 0.69$ \\
\hline
\end{tabular}

Values are presented as mean \pm standard deviation or number (\%).

rPMS, repetitive peripheral magnetic stimulation; BMI, body mass index; THA, total hip arthroplasty. 


\section{Comparison of VL strength}

The VL strength was evaluated with the RMS values measured at the VL during maximal isometric knee extension. The RMS values before stimulation were $48.82 \pm 11.17 \mu \mathrm{V}$ in the rPMS group and $51.18 \pm 11.40 \mu \mathrm{V}$ in the sham group, with no significant difference between the two groups ( $\mathrm{p}=0.65)$. The RMS values measured after 3 weeks of stimulation were $106.27 \pm 23.44 \mu \mathrm{V}$ in the rPMS group and $80.73 \pm 21.34 \mu \mathrm{V}$ in the sham group, with both groups showing a significant improvement after stimulation $(\mathrm{p}<0.05)$. However, for the degree of improvement between the two groups, the rPMS group had a significant improvement compared to the sham group $(\mathrm{p}<0.05)$ (Fig. 3).

\section{Comparison of the ratio of VL strength}

The ratio of VL strength was assessed by comparing the ratio of the RMS value of the VL on the fractured side to that of the VL on the unfractured side. The ratios before stimulation were $34.50 \% \pm 6.76 \%$ in the rPMS group and $36.80 \% \pm 74.82 \%$ in the sham group, with no significant difference between the two groups $(\mathrm{p}=0.40)$. The ratios measured after 3 weeks of stimulation were $70.51 \% \pm 5.87 \%$ in the rPMS group and $54.75 \% \pm 8.69 \%$ in the sham group, with both groups showing a significant improvement after stimulation $(\mathrm{p}<0.05)$. When evaluating the degree of enhancement between the two groups, the rPMS group showed a significant improvement compared to the sham group ( $\mathrm{p}<0.05)$ (Fig. 4).

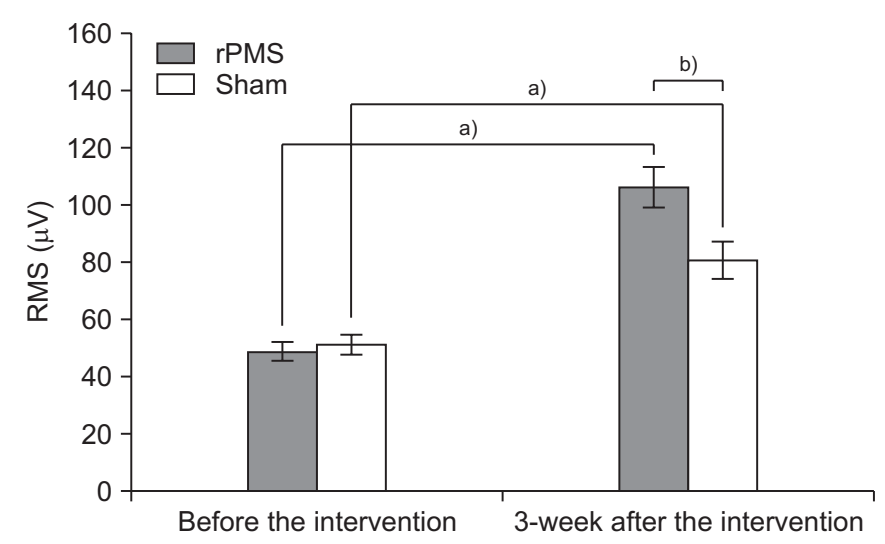

Fig. 3. The root mean square (RMS) value of the vastus lateralis in the fractured leg before and after stimulations. rPMS, repetitive peripheral magnetic stimulation. ${ }^{\text {a) }} \mathrm{p}<0.05$ by Wilcoxon signed-rank test compared with that before the intervention. ${ }^{\text {b) }} \mathrm{p}<0.05$ by Mann Whitney U-test compared with the sham group.

\section{Comparison of standing balance}

The standing balance was evaluated with the tandem stand test. The values from the tandem stand test before stimulation were $1.32 \pm 1.63 \mathrm{~s}$ in the rPMS group and $1.24 \pm 1.84 \mathrm{~s}$ in the sham group, with no significant difference between the two groups $(\mathrm{p}=0.90)$. The values from the tandem stand test measured after 3 weeks of stimulation were $8.21 \pm 1.81 \mathrm{~s}$ in the rPMS group and $5.96 \pm 2.51 \mathrm{~s}$ in the sham group, with both groups showing a significant improvement after stimulation $(\mathrm{p}<0.05)$. However, for the degree of improvement between the two groups,

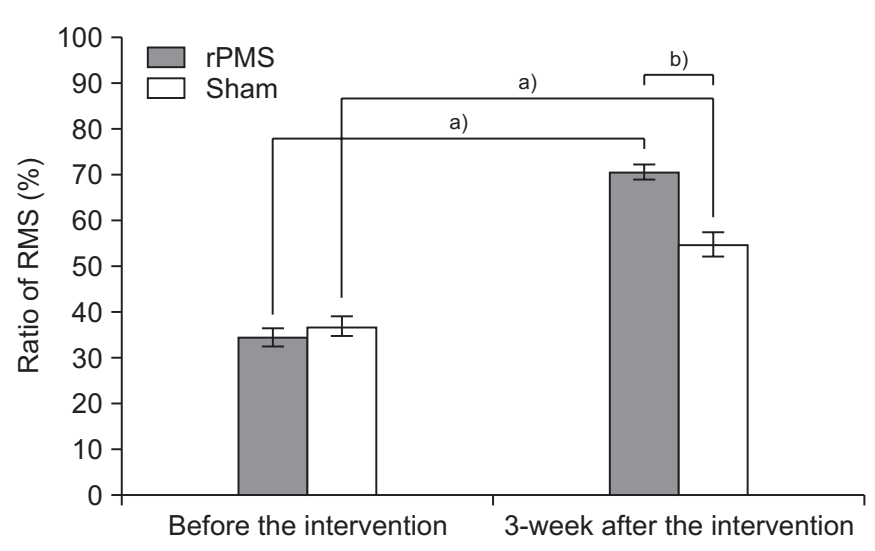

Fig. 4. The ratio of root mean square (RMS) values of the vastus lateralis between fractured and unfractured legs. rPMS, repetitive peripheral magnetic stimulation. ${ }^{\text {a) }} \mathrm{p}<0.05$ by Wilcoxon signed-rank test compared with that before the intervention. ${ }^{\text {b) }} \mathrm{p}<0.05$ by Mann-Whitney U-test compared with the sham group.

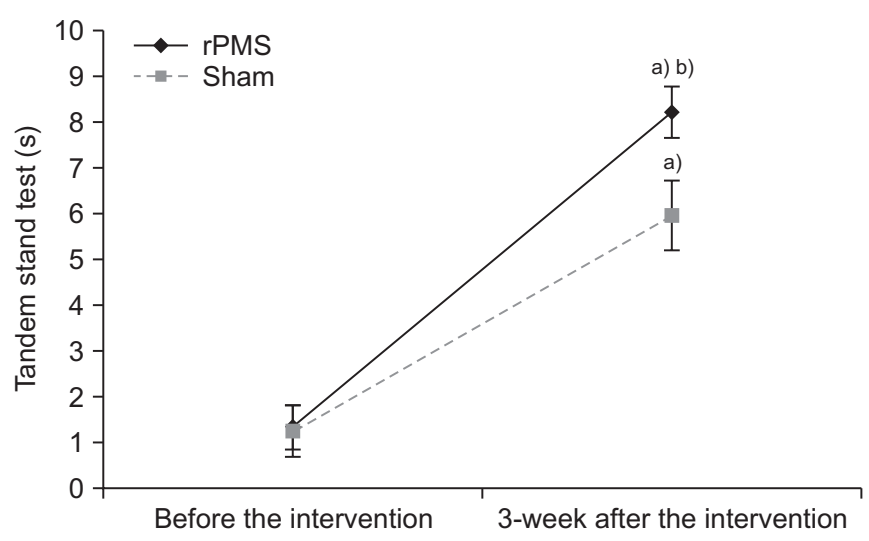

Fig. 5. Mean change of tandem stand test. rPMS, repetitive peripheral magnetic stimulation. ${ }^{\text {a) }} \mathrm{p}<0.05$ by Wilcoxon signed-rank test compared with that before the intervention. ${ }^{\text {b) }} \mathrm{p}<0.05$ by Mann-Whitney U-test compared with the sham group. 
the rPMS group had a significant improvement compared to the sham group $(\mathrm{p}<0.05)$ (Fig. 5).

\section{Comparison of gait function}

The gait function was assessed by usual gait speed. The values of usual gait speed before stimulation were $0.11 \pm 0.04 \mathrm{~m} / \mathrm{s}$ at $10 \mathrm{ft}, 0.13 \pm 0.03 \mathrm{~m} / \mathrm{s}$ at $50 \mathrm{ft}$ in the $\mathrm{rPMS}$ group and $0.12 \pm 0.04 \mathrm{~m} / \mathrm{s}$ at $10 \mathrm{ft}, 0.14 \pm 0.05 \mathrm{~m} / \mathrm{s}$ at $50 \mathrm{ft}$ in the sham group, with no significant differences between the two groups $(p=0.52, p=0.90)$. The values of usual gait speed measured after 3 weeks of stimulation were $0.41 \pm 0.12 \mathrm{~m} / \mathrm{s}$ at $10 \mathrm{ft}, 0.41 \pm 0.15 \mathrm{~m} / \mathrm{s}$ at $50 \mathrm{ft}$ in the $\mathrm{rPMS}$ group and $0.32 \pm 0.05 \mathrm{~m} / \mathrm{s}$ at $10 \mathrm{ft}, 0.31 \pm 0.08 \mathrm{~m} / \mathrm{s}$ at $50 \mathrm{ft}$ in the sham group, with both groups showing a significant improvement after stimulation $(\mathrm{p}<0.05)$. However, for the degree of improvement between the two groups, the rPMS group had a significant improvement compared to the sham group $(\mathrm{p}<0.05)$ (Fig. 6).

\section{Comparison of pain}

The pain was evaluated by a VAS. The values of VAS before stimulation were $4.09 \pm 0.94$ in the rPMS group and $4.18 \pm 1.33$ in the sham group, with no significant difference between the two groups $(\mathrm{p}=0.85)$. The values of the VAS measured after 3 weeks of stimulation were $1.91 \pm 0.70$ in the rPMS group and 2.18 \pm 1.08 in the sham group, with both groups showing a significant improvement after stimulation $(\mathrm{p}<0.05)$, but with no significant difference between the two groups $(\mathrm{p}=0.75)$.

(A)

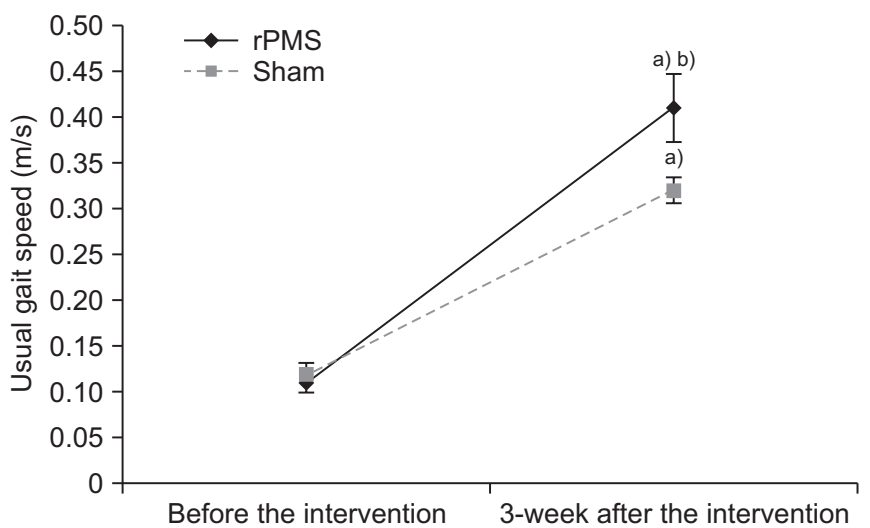

\section{DISCUSSION}

In this study, we found a significant improvement in VL strength after 3 weeks of rPMS when evaluated with surface EMG technique. Surface EMG technique is a method to capture the electrical muscle signal that occurs during muscle contraction and to quantify the degree of electrical activity using RMS, and its value is higher when muscle strength is higher [27]. In particular, the VL was chosen as the subject for stimulation, as it is known to have a linear relationship with the actual force among three superficial quadriceps muscles [23].

One of the major mechanisms by which rPMS strengthens the muscle is the neuromodulation effect of rPMS. Magnetic stimulation applied to the muscle belly can contract the muscle by stimulating the axon of the intramuscular motor neuron [12]. Repeated magnetic stimulation on the muscle can indirectly activate type $\mathrm{Ia}, \mathrm{Ib}$ and II afferent nerve fibers by creating rhythmic contraction and relaxation like vibration [13]. In addition, rPMS can produce sensory input by directly stimulating the proprioceptive afferent nerve fiber even without muscle contraction [14]. As such, the large proprioceptive data produced by rPMS, directly and indirectly, are entered into the opposite somatosensory area through the spinal circuit, and this signal, in turn, is transferred through the corticocortical or thalamocortical tract, increasing the excitability of the motor cortex related to the stimulated site. As the basis for this, Struppler et al. [15] reported that rPMS increase regional cerebral blood flow to the contra-

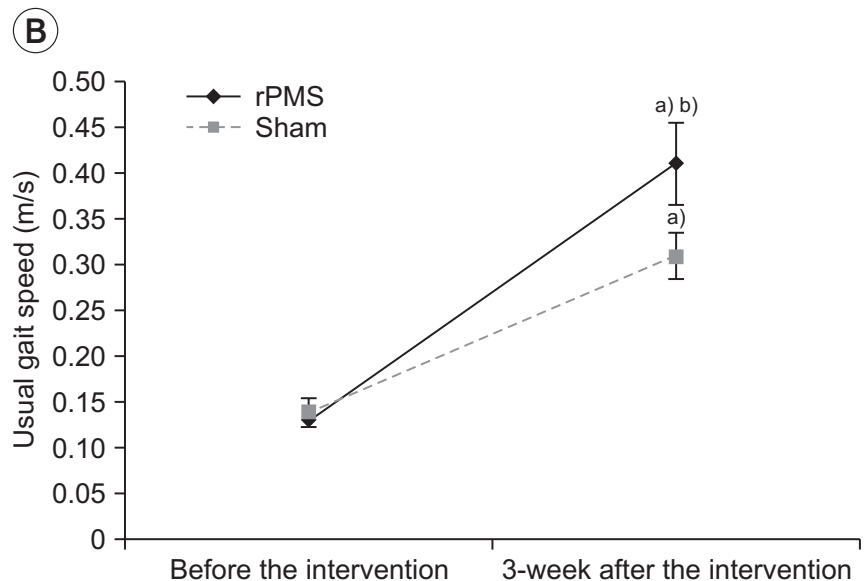

Fig. 6. Mean change of usual gait speed measured over the $10 \mathrm{ft}(\mathrm{A})$ and the $50 \mathrm{ft}(\mathrm{B})$. rPMS, repetitive peripheral magnetic stimulation. ${ }^{\text {a) }} \mathrm{p}<0.05$ by Wilcoxon signed-rank test compared with that before the intervention. ${ }^{\text {b) }} \mathrm{p}<0.05$ by Mann-Whitney U-test compared with the sham group. 
lateral fronto-parietal area through a positron emission tomography. Gallasch et al. [16] also reported that the activities of the contralateral sensorimotor cortex and the corticospinal tract increase after rPMS, using functional magnetic resonance imaging and motor evoked potentials. It is therefore thought that rPMS increase motor cortical excitability by facilitating the reorganization of the central nervous system through the activation of the afferent sensory pathway and eventually improving the strength and performance of the stimulated muscle. In this study, it is considered that 3 weeks of rPMS strengthened the muscle strength of the VL through the mechanism mentioned above. Our result is consistent with that of Bustamante et al. [21] who reported that the voluntary quadriceps strength and exercise capacity of patients with chronic obstructive pulmonary disease improved after applying rPMS to the quadriceps although there are differences in the type of coil and the frequency, intensity and duration of stimulation.

Tandem standing time for the experiment group with 3 weeks of rPMS significantly increased compared to that of the control group. Guralnik et al. [24] proposed the use of the tandem stand test to measure the standing balance of elderly people and suggested that smaller difference in muscle strength between the two legs, as well as a higher strength of both legs, are important in maintaining a longer period of a tandem stand position. Lamb et al. [26] reported that the increase of the leg extensor power ratio between fractured and unfractured legs improved standing balance after electrical stimulation on the quadriceps after hip fracture, although there is no difference in the leg strength between two groups. In this study, it is thought that the significant increase of tandem standing time in rPMS group is attributable to both the rise of VL strength itself and the improvement of the ratio of VL strength between both legs.

The usual gait speed of rPMS group was significantly faster than that of the control group. The gait speed is one of the objective assessments frequently used to evaluate the functional limitation of elderly people and is especially known to be useful as a predictor for future functional independence [25]. Ferrucci et al. [28] reported that the usual gait speed is faster when the strength of both legs is higher and that in particular, knee extensor strength has a linear relationship with gait speed. In addition, Buchner et al. [29] suggested that the increase of gait speed through the improvement of muscle strength is more significant in frail elderly people with lower strength in both legs than in healthy elderly people. Therefore, the reason for the increased usual gait speed of the experimental group was due to the fact that knee extensor strength significantly increased after rPMS in the frail state after surgery.

However, no significant difference was found in VAS, which was measured to assess the degree of hip pain, between the two groups. Although a few studies reported that rPMS might reduce the musculoskeletal pain, such the effect occurred when rPMS was applied to the tender point or the proximal part of the nerve to the painful areas $[22,30]$. But the reason why there is no difference in our study could be because rPMS was applied not to the tender point but to the motor point.

There are some limitations of this study. First, the number of subjects was small. Second, the experimental period was short. Three weeks is considered too short to induce hypertrophy, and so we did not evaluate the effect of rPMS on muscle mass size through radiologic tools. The supplementary investigations are needed to have larger subjects and longer period. Finally, we could not define the optimal rPMS protocol due to variations in stimulation frequency, intensity, and duration.

In this study, rPMS on the VL for 3 weeks in the early stage after hip surgery significantly improved muscle strength, standing balance and gait function. Therefore, we recommend that rPMS could be applied for patients in the first stage after hip replacement surgery, who cannot tolerate a sufficient intensity of electrical stimulation to induce muscle contraction or attach electrical pads due to the unhealed wound.

\section{CONFLICT OF INTEREST}

No potential conflict of interest relevant to this article was reported.

\section{REFERENCES}

1. Kannus P, Parkkari J. Prevention of hip fracture with hip protectors. Age Ageing 2006;35 Suppl 2:ii51-4.

2. Peeters CM, Visser E, Van de Ree CL, Gosens T, Den Oudsten BL, De Vries J. Quality of life after hip fracture in the elderly: a systematic literature review. In- 
jury 2016;47:1369-82.

3. Kim JL, Jung JS, Kim SJ. Prediction of ambulatory status after hip fracture surgery in patients over 60 years old. Ann Rehabil Med 2016;40:666-74.

4. Mitchell SL, Stott DJ, Martin BJ, Grant SJ. Randomized controlled trial of quadriceps training after proximal femoral fracture. Clin Rehabil 2001;15:282-90.

5. Aniansson A, Zetterberg C, Hedberg M, Henriksson KG. Impaired muscle function with aging: a background factor in the incidence of fractures of the proximal end of the femur. Clin Orthop Relat Res 1984;(191):193-201.

6. Lamb SE, Morse RE, Evans JG. Mobility after proximal femoral fracture: the relevance of leg extensor power, postural sway and other factors. Age Ageing 1995;24:308-14.

7. Lee YH. Functional electrical stimulation. J Korean Acad Rehabil Med 2001;25:1-11.

8. Chipchase LS, Schabrun SM, Hodges PW. Peripheral electrical stimulation to induce cortical plasticity: a systematic review of stimulus parameters. Clin Neurophysiol 2011;122:456-63.

9. Schuhfried O, Crevenna R, Fialka-Moser V, Paternostro-Sluga T. Non-invasive neuromuscular electrical stimulation in patients with central nervous system lesions: an educational review. J Rehabil Med 2012;44:99-105.

10. Braid V, Barber M, Mitchell SL, Martin BJ, Granat M, Stott DJ. Randomised controlled trial of electrical stimulation of the quadriceps after proximal femoral fracture. Aging Clin Exp Res 2008;20:62-6.

11. Struppler A, Angerer B, Havel P. Modulation of sensorimotor performances and cognition abilities induced by RPMS: clinical and experimental investigations. Suppl Clin Neurophysiol 2003;56:358-67.

12. Machetanz J, Bischoff C, Pichlmeier R, Riescher H, Meyer BU, Sader A, et al. Magnetically induced muscle contraction is caused by motor nerve stimulation and not by direct muscle activation. Muscle Nerve 1994;17:1170-5.

13. Zhu Y, Starr A. Magnetic stimulation of muscle evokes cerebral potentials. Muscle Nerve 1991;14:721-32.

14. Zhu Y, Starr A, Haldeman S, Fu H, Liu J, Wu P. Magnetic stimulation of muscle evokes cerebral potentials by direct activation of nerve afferents: a study during muscle paralysis. Muscle Nerve 1996;19:1570-5.
15. Struppler A, Binkofski F, Angerer B, Bernhardt M, Spiegel S, Drzezga A, et al. A fronto-parietal network is mediating improvement of motor function related to repetitive peripheral magnetic stimulation: a PETH2O15 study. Neuroimage 2007;36 Suppl 2:T174-86.

16. Gallasch E, Christova M, Kunz A, Rafolt D, Golaszewski S. Modulation of sensorimotor cortex by repetitive peripheral magnetic stimulation. Front Hum Neurosci 2015;9:407.

17. Han TR, Shin HI, Kim IS. Magnetic stimulation of the quadriceps femoris muscle: comparison of pain with electrical stimulation. Am J Phys Med Rehabil 2006;85:593-9.

18. Barker AT, Freeston IL, Jalinous R, Jarratt JA. Magnetic stimulation of the human brain and peripheral nervous system: an introduction and the results of an initial clinical evaluation. Neurosurgery 1987;20:100-9.

19. Szecsi J, Schiller M, Straube A, Gerling D. A comparison of functional electrical and magnetic stimulation for propelled cycling of paretic patients. Arch Phys Med Rehabil 2009;90:564-70.

20. Amassian VE, Maccabee PJ, Cracco RQ. Focal stimulation of human peripheral nerve with the magnetic coil: a comparison with electrical stimulation. Exp Neurol 1989;103:282-9.

21. Bustamante V, Lopez de Santa Maria E, Gorostiza A, Jimenez U, Galdiz JB. Muscle training with repetitive magnetic stimulation of the quadriceps in severe COPD patients. Respir Med 2010;104:237-45.

22. Pujol J, Pascual-Leone A, Dolz C, Delgado E, Dolz JL, Aldoma J. The effect of repetitive magnetic stimulation on localized musculoskeletal pain. Neuroreport 1998;9:1745-8.

23. Alkner BA, Tesch PA, Berg HE. Quadriceps EMG/force relationship in knee extension and leg press. Med Sci Sports Exerc 2000;32:459-63.

24. Guralnik JM, Simonsick EM, Ferrucci L, Glynn RJ, Berkman LF, Blazer DG, et al. A short physical performance battery assessing lower extremity function: association with self-reported disability and prediction of mortality and nursing home admission. J Gerontol 1994;49:M85-94.

25. Guralnik JM, Ferrucci L. Assessing the building blocks of function: utilizing measures of functional limitation. Am J Prev Med 2003;25(3 Suppl 2):112-21.

26. Lamb SE, Oldham JA, Morse RE, Evans JG. Neuro- 
muscular stimulation of the quadriceps muscle after hip fracture: a randomized controlled trial. Arch Phys Med Rehabil 2002;83:1087-92.

27. Fukuda TY, Echeimberg JO, Pompeu JE, Lucareli PR, Garbelotti S, Gimenes RO, et al. Root mean square value of the electromyographic signal in the isometric torque of the quadriceps, hamstrings and brachial biceps muscles in female subjects. J Appl Res 2010;10:32-9.

28. Ferrucci L, Guralnik JM, Buchner D, Kasper J, Lamb SE, Simonsick EM, et al. Departures from linearity in the relationship between measures of muscular strength and physical performance of the lower extremities: the Women's Health and Aging Study. J Gerontol A Biol Sci Med Sci 1997;52:M275-85.

29. Buchner DM, Larson EB, Wagner EH, Koepsell TD, de Lateur BJ. Evidence for a non-linear relationship between leg strength and gait speed. Age Ageing 1996;25:386-91.

30. Khedr EM, Ahmed MA, Alkady EA, Mostafa MG, Said HG. Therapeutic effects of peripheral magnetic stimulation on traumatic brachial plexopathy: clinical and neurophysiological study. Neurophysiol Clin 2012;42:111-8. 